\title{
Soroprevalência e fatores de risco associados ao herpesvírus bovino tipo 1 e ocorrência da infecção pelo vírus da diarreia viral bovina em vacas leiteiras no estado de Pernambuco
}

\author{
[Seroprevalence and risk factors for bovine herpesvirus type 1 and occurrence of bovine viral \\ diarrhea virus infections in dairy cows in Pernambuco]
}

\section{"Artigo Científico/Scientific Article"}

\author{
Bruno Pajeú e Silva ${ }^{1 *}$, Larice Bruna Ferreira Soares ${ }^{2}$, Allison Alves de Macêdo ${ }^{2}$, \\ Júnior Mário Baltazar de Oliveira ${ }^{1}$, Breno Bezerra Aragão ${ }^{1}$, Sérgio Alves do Nascimento ${ }^{1}$, \\ José Wilton Pinheiro Junior ${ }^{1}$
}

\begin{abstract}
${ }^{1}$ Departamento de Medicina Veterinária, Universidade Federal Rural de Pernambuco, Recife-PE, Brasil.
${ }^{2}$ Departamento de Medicina Veterinária, Unidade Acadêmica de Garanhuns, Universidade Federal Rural de Pernambuco, Garanhuns-PE, Brasil.

*Autor para correspondência/Corresponding author: E-mail: bruno_pajeu@ hotmail.com
\end{abstract}

\section{Resumo}

Objetivou-se, com este estudo, determinar a soroprevalência para a infecção pelo herpesvírus bovino tipo 1 (HVB-1) e vírus da diarreia viral bovina (VDVB-1) e identificar os fatores de risco associados à infecção HVB-1 em vacas leiteiras na bacia leiteira do estado de Pernambuco. Foram analisadas 358 amostras de soro sanguíneo provenientes de vacas leiteiras em idade reprodutiva, não vacinados para os referidos agentes, procedentes de 18 propriedades, distribuídas em seis municípios na microrregião do Vale do Ipanema, Pernambuco. Para o diagnóstico sorológico foi utilizada a técnica de vírusneutralização. A ocorrência de anticorpos anti-HVB-1 em bovinos foi 52,8\% (188/356), enquanto que para VDVB-1 foi 99,4\% (355/357). Observou-se uma variação da ocorrência de anticorpos, por propriedade, de 5 a 90,9\% para HVB-1 e 93,5 a $100 \%$ para VDVB-1, destacando-se que $100 \%$ das propriedades possuíam ao menos um animal positivo para as duas infecções. Os fatores de risco associados à infecção por HVB-1 foram: compartilhamento de pastos $(\mathrm{OR}=2,9 ; \mathrm{p}=0,004)$; não utilização de inseminação artificial $(\mathrm{OR}=2,3 ; \mathrm{p}<0,001)$; não realização de transferência de embriões $(\mathrm{OR}=13,6 ; \mathrm{p}<0,001)$; aquisição de animais destinados à reprodução $(\mathrm{OR}=4,2 ; \mathrm{p}$ $<0,001)$; reposição de animais da mesma região $(\mathrm{OR}=3,0 ; \mathrm{p}=0,001)$ e fetos abortados deixados no pasto $(\mathrm{OR}=4,0 ; \mathrm{p}<0,001)$. É possível concluir que a infecção por ambos os agentes está distribuída nos bovinos da área do estudo, sendo necessária a implementação de medidas preventivas a partir dos fatores de risco identificados no presente estudo.

Palavras-chave: HVB-1; VDVB-1; doença reprodutiva; epidemiologia; bacia leiteira.

\begin{abstract}
This study aimed to determine the seroprevalence and risk factors for bovine herpesvirus type 1 (BoHV-1) and the occurrence of bovine viral diarrhea virus (BVDV-1) infections in dairy cows in the dairy basins of Pernambuco. A total of 358 blood serum samples from non-vaccinated dairy cows from 18 farms, distributed in six municipalities in Vale do Ipanema, Pernambuco, were analyzed. For the serological diagnosis, the virus neutralization technique was used. The occurrences of anti-BoHV-1 and anti-BVDV-1 antibodies in cattle were $52.8 \%$ (188/356) and 99.4\% (355/357), respectively. The ranges of occurrence of anti-BoHV-1 and antiBVDV-1 antibodies were 5\%-90.9\% and $93.5 \%-100 \%$, respectively, with $100 \%$ of the farms having at least one animal positive for both infections. Risk factors for BoHV-1 infection were pasture sharing (odds ratio $[\mathrm{OR}]=2.9 ; p=0.004)$, no use of artificial insemination $(\mathrm{OR}=2.3 ; p<0.001)$, no embryo transfer $(\mathrm{OR}=13.6$; $p<0.001)$, acquisition of breeding animals $(\mathrm{OR}=4.2 ; p<0.001)$, replacement of animals from the same region $(\mathrm{OR}=3.0 ; p=0.001)$, and aborted fetuses left in the pasture $(\mathrm{OR}=4.0 ; p<0.001)$. The findings suggested the presence of both viral infections in the cattle in the study area. Therefore, implementation of preventive measures based on the risk factors identified in the present study is necessary.
\end{abstract}

Keywords: BoHV-1; BVDV; reproductive disease; epidemiology; dairy basin. 


\section{Introdução}

A rinotraqueíte infecciosa bovina (RIB), causada pelo herpesvírus bovino tipo 1 (HVB-1), e a diarreia viral bovina (DVB), causada pelo vírus da diarreia viral bovina (VDVB-1), são enfermidades virais altamente contagiosas, amplamente distribuídas em bovinos em diversas partes do mundo (Baker, 1995; Nandi et al., 2009; Romero-Salas et al., 2013; Sayers et al., 2015).

A prevalência média da infecção por HVB-1 no Brasil, entre 2000 a 2015 , foi $55,28 \%$, variando de $17,5 \%$ (Oliveira et al., 2015) a $84,5 \%$ (Holz et al., 2009), enquanto que a ocorrência da infecção pelo VDVB-1 em rebanhos bovinos nacionais varia entre 14,6\% (Ribeiro et al., 1987) e 72,6\% (Castro et al., 1993), ficando a prevalência geral em torno de 65,6\% (Chaves et al., 2012).

Os prejuízos ocasionados pelo alphaherpesvírus bovino tipo 1, no tocante aos aspectos reprodutivos, estão associados à surtos de abortos e infertilidade devido à vulvovaginite pustular infecciosa (VPI) em fêmeas e balanopostite pustular infecciosa (BPI) nos machos (Muylkens et al., 2007; Nandi et al., 2009). Da mesma forma, dependendo do tipo de isolado presente na população, a infecção pelo VDVB-1 pode ocasionar desde infecções inaparentes ou sinais clínicos brandos (Evans et al., 2016) à ocorrência de severas perdas reprodutivas, como abortos, natimortos, morte precoce dos bezerros, assim como o nascimento de animais persistentemente infectados (PI) (Grooms, 2004). Em um estudo realizado por Kirkbride (1992), foram examinados 8.962 fetos provenientes de abortos, dentre os quais 948 (10,58\%) foram atribuídos a agentes virais, sendo $485(51,1 \%)$ desses atribuídos ao HVB-1 e 407 (42,3\%) ao VDVB-1, o que evidencia a importância desses vírus no tocante às falhas reprodutivas, especificamente o aborto.

Tendo em vista os impactos reprodutivos causados pelo HBV-1 e VDVB-1 à bovinocultura leiteira e a falta de informações desses agentes na região estudada - onde a atividade leiteira tem forte apelo econômico, social e cultural -, objetivou-se com este estudo determinar a prevalência do HVB1 e VDVB-1 e os principais fatores de risco associados à infecção pelo HVB-1.

\section{Material e Métodos}

$\mathrm{O}$ estudo foi realizado na Microrregião do Vale do Ipanema, com uma área de $5.456 \mathrm{Km}^{2}$, localizada entre as coordenadas S $8^{\circ} 24^{\prime} 00,0^{\prime \prime}$ - $9^{\circ} 21^{\prime} 60,0$ e W 37033'60,0' - 36'43'20,0', A microrregião, considerada a bacia leiteira do estado de Pernambuco, é composta por seis municípios: Águas Belas, Buíque, Itaíba, Pedra, Tupanatinga e Venturosa (BRASIL, 2015).

Para compor a amostra do estudo foi considerada uma população de bovinos leiteiros de 87.094 cabeças (BRASIL, 2015) e uma prevalência esperada de 79,5\% (Silva et al., 2015) para HVB1 , e de $65,6 \%$ (Chaves et al., 2012) para VDVB, com intervalo de confiança de $95 \%$ e erro estatístico de 5\%, o que forneceu uma amostragem mínima de 250 e 346 animais para HVB-1 e VDVB-1, respectivamente (Thrusfield, 2004). O número de animais por propriedade foi determinado considerando o número de vacas em idade reprodutiva, utilizando os parâmetros supracitados.

Foram coletadas 358 amostras de vacas com idade igual ou superior a 24 meses entre o período de dezembro de 2015 a fevereiro de 2016, não vacinadas para RBI ou DVB, distribuídas em 18 propriedades nos seis municípios.

As amostras de sangue, destinadas à sorologia, foram coletadas por meio de venopunção da coccígea com agulhas descartáveis em tubos com vácuos previamente identificados. $\mathrm{O}$ soro foi separado do sangue total por centrifugação a $900 \mathrm{x}$ g por 15 minutos e acondicionados em microtubos plásticos a $-20^{\circ} \mathrm{C}$ para posterior análise.

Foram processadas 358 amostras por meio da técnica de virusneutralização como descrito e preconizado pela OIE (2012). As amostras de soro foram inativadas em banho maria a $56^{\circ} \mathrm{C}$ durante 30 minutos, e, em seguida, distribuídas em microplacas de 96 poços em duplicata para realização da técnica nas diluições de 1:2 e 1:4. O teste foi realizado em células de linhagem contínua Madin Darby Bovine Kidney (MDBK) cultivadas em meio essencial mínimo MEM, suplementado com soro fetal bovino $2 \%$.

Como antígeno, foram utilizadas uma amostra de HVB-1 cepa Los Angeles e uma de VDVB-1 cepa NADL, ambas provenientes da Universidade Federal Rural de Pernambuco, na dose infectante de $100 \mathrm{TCID}_{50}$ por poço.

As amostras formam distribuídas nas microplacas juntamente com os respectivos vírus HVB-1 e VDVB previamente titulados - e incubadas para posteriormente receberem as células MDBK, sendo mantidas em estufa a $37^{\circ} \mathrm{C} \mathrm{e}$ 
tensão de $\mathrm{CO}_{2}$ a $5 \%$, de acordo com o preconizado pela OIE (2012). As placas foram avaliadas a cada 24 horas e o resultado final foi emitido transcorridas 72 horas para o HVB-1 e 96 horas para o VDVB-1.

Foram realizados controles positivos e negativos do vírus e das células, respectivamente, em cada microplaca, sendo avaliados os efeitos citopáticos dos controles antes da leitura das amostras em placa. Foi realizada para todos os testes de virusneutralização uma retrotitulação viral para verificação e validação das provas.

As amostras consideradas positivas para a presença de anticorpos foram aquelas que apresentaram inibição da lise celular na diluição de 1:4, sendo descartadas as amostras que apresentaram efeito citotóxico no cultivo celular. Perfazendo um total de 356 amostras válidas para anticorpos anti-HVB-1 e 357 para anticorpos antiVDVB-1.

Para o estudo dos fatores de risco foi utilizado um questionário investigativo epidemiológico constituído de perguntas objetivas, relativas às informações sobre tipo de produção, sistema de manejo, status sanitário do rebanho e manejo reprodutivo.

Para identificar os possíveis fatores de risco associados à infecção, realizou-se uma análise univariada das variáveis de interesse pelo teste quiquadrado de Pearson ou exato de Fisher. Posteriormente, foi realizada uma análise de regressão logística considerando como variável dependente a virusneutralização (positivo ou negativo). As variáveis independentes ou explanatórias consideradas no modelo foram aquelas que apresentaram significância estatística $<0,20$. Essa probabilidade foi estipulada para que possíveis fatores de risco do evento não fossem excluídos da análise (Hosmer e Lemeshow, 1989).
Considerou-se como fatores de risco no modelo final as variáveis que apresentaram valor de $\mathrm{p}<0,05$. O EpiInfo ${ }^{\mathrm{TM}} 7$ foi utilizado para a execução dos cálculos estatísticos e o nível de significância adotado foi de $5 \%$.

Foi realizada uma escala de ocorrência de acordo com os percentis da pesquisa de anticorpos anti-HVB-1 e anti-VDVB-1, utilizando o programa EpiInfo $^{\mathrm{TM}}$ 7, classificando as propriedades como de baixa ocorrência para aquelas que apresentaram valor menor que $43,4 \%$; média ocorrência com valores entre $43,4-80,3 \%$ e alta ocorrência com valores acima de $80,3 \%$.

\section{Resultados}

A ocorrência de anticorpos anti-HVB-1 em bovinos foi 52,8\% (188/356) e para anticorpos antiVDVB-1 foi 99,44\% (355/357). Em relação ao número de animais positivos por propriedades, observou-se uma variação da ocorrência de anticorpos anti-HVB-1 de 5 a 90,9\%, enquanto que a variação de anticorpos anti-VDVB-1 foi 93,7 a $100 \%$. Destaca-se que $100 \%$ das propriedades possuíam ao menos um animal positivo tanto para anticorpos anti-HVB-1 quanto para anti-VDVB-1 (Figura 1).

Somente quatro propriedades, dentre as 18 amostradas, foram classificadas como sendo de baixa ocorrência de anticorpos anti-HVB-1, com valores variando de 5 a $37,5 \%$. Dez propriedades foram classificadas como de média ocorrência, cujos valores variaram desde $45,4 \%$ ao limite de $80 \%$. As demais quatro propriedades, apresentaram valores altos, variando de $81,5 \%$ a $90,9 \%$, sendo classificadas como de alta ocorrência. Com relação ao VDVB-1, constatou-se uma positividade acima de $93,7 \%$, sendo que das 18 propriedades, 16 apresentaram positividade de 100\% (Figura 1).

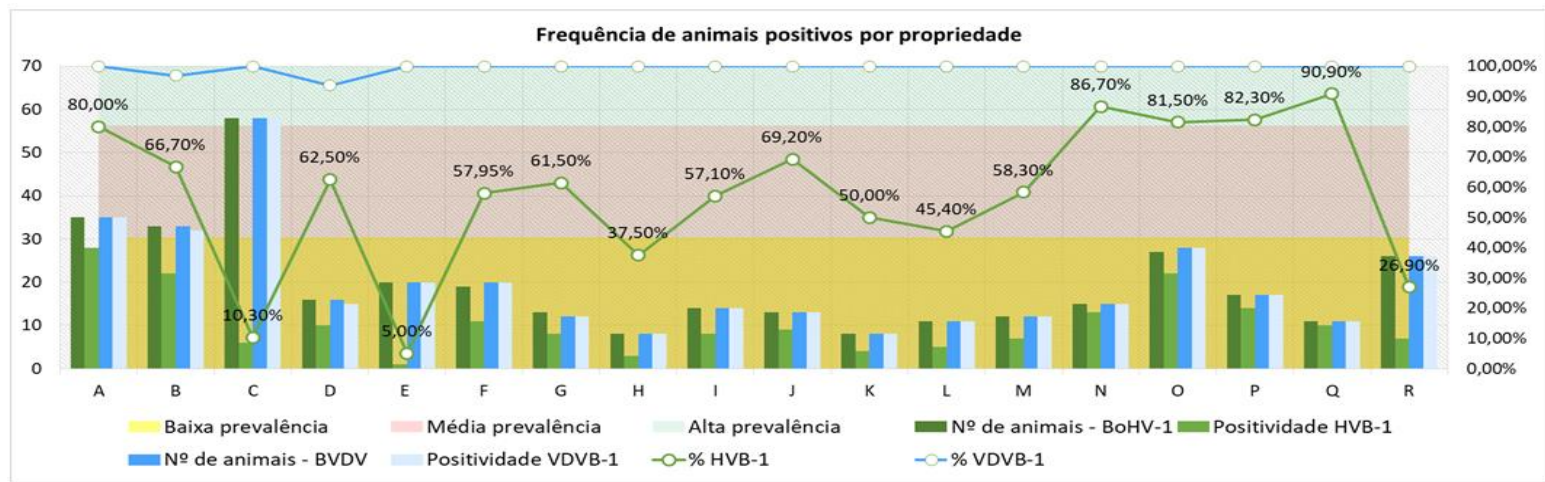

Figura 1. Ocorrência de vacas positivas para anticorpos anti-BVDV-1 e anti-BoHV-1 por propriedade na microrregião do Vale do Ipanema, estado de Pernambuco, no período de dezembro de 2015 a fevereiro de 2016. 
A análise dos fatores de risco associados à infecção pelo HVB-1 está disposta na Tabela 1. Foram considerados fatores de risco: compartilhamento de pastagem; não utilização de inseminação artificial; não realização de transferência de embriões; aquisição e venda de animais destinados à reprodução; reposição de animais da mesma região e fetos abortados deixados no pasto.

Em decorrência do elevado percentual de animais positivos para anticorpos anti-VDVB-1, não foi possível a classificação das propriedades por valores de ocorrência.

Tabela 1. Análise de fatores de risco associados à infecção pelo BoHV-1 em bovinos da microrregião do Vale do Ipanema, estado de Pernambuco, de dezembro de 2015 a fevereiro de 2016.

\begin{tabular}{|c|c|c|c|c|c|c|}
\hline Variáveis & & $\mathbf{N}$ & $\begin{array}{l}\text { Sorologia } \\
\text { Positiva }\end{array}$ & Valor p & $\begin{array}{c}\text { Regressão } \\
\text { logística OR } \\
\text { (I.C. 95\%) }\end{array}$ & Valor p \\
\hline \multicolumn{7}{|c|}{ Manejo Produtivo } \\
\hline \multirow[t]{2}{*}{ Sistema de criação } & $\begin{array}{c}\text { Semi- } \\
\text { intensivo }\end{array}$ & 333 & $176(52,8 \%)$ & $0,949^{(\mathrm{A})}$ & & \\
\hline & Extensivo & 23 & $12(52,2 \%)$ & & & \\
\hline $\begin{array}{l}\text { Criação de } \\
\text { caprinos/ovinos }\end{array}$ & Sim & 207 & $106(51,2 \%)$ & $0,475^{(\mathrm{A})}$ & & \\
\hline \multirow[t]{2}{*}{ Aluguel de pastagens } & Sim & 207 & $109(52,6 \%)$ & $0,946^{(\mathrm{A})}$ & & \\
\hline & Não & 149 & $79(53,0 \%)$ & & & \\
\hline Pastagem & Sim & 64 & $47(73,4 \%)$ & $<0,001^{(\mathrm{A})}$ & $2,9(1,6-5,4)$ & $0,004 *$ \\
\hline compartilhada & Não & 292 & $141(48,3 \%)$ & $*$ & & \\
\hline \multirow[t]{2}{*}{ Ordenha mecânica } & Sim & 187 & $94(50,3 \%)$ & $0,313^{(\mathrm{A})}$ & & \\
\hline & Não & 169 & $94(55,6 \%)$ & & & \\
\hline Importa animais de & Sim & 175 & $98(56,0 \%)$ & $0,236^{(\mathrm{A})}$ & & \\
\hline outros rebanhos & Não & 181 & $90(49,7 \%)$ & & & \\
\hline Reposição de animais & Sim & 278 & $131(47,1 \%)$ & $<0,001^{(\mathrm{A})}$ & $3,0(1,7-5,3)$ & $0,001 *$ \\
\hline da mesma região & Não & 78 & $57(73,1 \%)$ & $*$ & & \\
\hline \multicolumn{7}{|c|}{ Manejo Reprodutivo } \\
\hline Utiliza inseminação & Sim & 112 & $43(38,4 \%)$ & $<0,001^{(\mathrm{A})}$ & $2,3(1,5-3,7)$ & $<0,001 *$ \\
\hline artificial & Não & 244 & $145(59,4 \%)$ & $*$ & & \\
\hline Utiliza transferência de & Sim & 58 & $6(10,3 \%)$ & $<0,001^{(\mathrm{A})}$ & $13,6(5,6-32,6)$ & $<0,001 *$ \\
\hline embriões & Não & 298 & $182(61,1 \%)$ & $*$ & & \\
\hline Utiliza reprodutores na & Sim & 264 & $163(61,7 \%)$ & $0,678^{(\mathrm{A})}$ & & \\
\hline propriedade ${ }^{1}$ & Não & 26 & $15(57,7 \%)$ & & & \\
\hline Utiliza touro de repasse & Sim & 336 & $177(52,7 \%)$ & $0,700^{(\mathrm{A})}$ & & \\
\hline 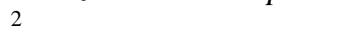 & Não & 12 & $7(58,3 \%)$ & & & \\
\hline Aquisição de animais & Sim & 192 & $132(68,7 \%)$ & $<0,001^{(\mathrm{A})}$ & $4,2(2,7-6,6)$ & $<0,001 *$ \\
\hline para reprodução & Não & 164 & $56(34,1 \%)$ & $*$ & & \\
\hline Venda de animais para & Sim & 269 & $155(57,2 \%)$ & $0,001^{(\mathrm{A}) *}$ & $2,2(1,3-3,6)$ & $0,001 *$ \\
\hline reprodução & Não & 87 & $33(37,9 \%)$ & & & \\
\hline \multicolumn{7}{|c|}{ Manejo Sanitário } \\
\hline \multirow[t]{2}{*}{$\begin{array}{l}\text { Destino dos fetos } \\
\text { abortados }^{3}\end{array}$} & $\begin{array}{l}\text { Queima/ } \\
\text { enterra }\end{array}$ & 126 & $41(32,5 \%)$ & $\begin{array}{c}<0,001^{(\mathrm{A})} \\
*\end{array}$ & $4,0(2,5-6,5)$ & $<0,001 *$ \\
\hline & Pastagem & 192 & $127(66,1 \%)$ & & & \\
\hline
\end{tabular}

\section{Discussão}

A ocorrência de anticorpos anti-HVB-1 em bovinos encontrada no presente estudo $(52,8 \%)$ está em consonância com outros estudos realizados em outras partes do país, como no Paraná (Dias et al., 2013), no Espírito Santo (Santos et al., 2014), em Goiás (Barbosa et al., 2005) e no Maranhão (Freitas et al., 2014), o que demonstra que a infecção pelo HVB-1 está distribuída em bovinos, não somente em Pernambuco, como também em todo Brasil. Apesar de constatada a ocorrência nos rebanhos nacionais, não existe um programa oficial de controle e prevenção para IBR, o que pode contribuir para altas taxas de prevalência da infecção, já que a doença ocorre muitas vezes de forma subclínica e ocorre a comercialização de 
animais infectados, favorecendo a transmissão do vírus entre rebanhos.

Com relação à ocorrência de anticorpos antiVDVB-1, constatou-se que o valor encontrado $(99,44 \%)$ está acima da média de outros estudos no Brasil e no mundo (Chaves et al., 2012; Chowdhury et al., 2015; Evans et al., 2016). A expectativa para a ocorrência de anticorpos antiVDVB-1 é elevada em alguns países como a Irlanda (Sayers et al., 2015) e Uruguai (Guarino et al., 2008), com 70 e $100 \%$, respectivamente. Houe et al. (1995) destacam que a alta ocorrência de animais positivos é um forte indicador da presença de animais persistentemente infectados (PI) no rebanho, o que constitui um fator importante na cadeia epidemiológica referente à manutenção e disseminação do VDVB-1. Além da presença de animais PI, a ocorrência de propriedades separadas apenas por uma cerca, somado a fatores culturais já consolidados, como o intercâmbio de animais entre propriedades sem controle sanitário, são determinantes para os elevados índices de soropositividade.

Graham et al. (2016) destacam como importante fator de risco a compra de animais com status sanitário desconhecido ou a compra de fêmeas gestantes que possam estar gestando fetos PI; bem como a proximidade com rebanhos positivos, não excluindo-se o compartilhamento de pastos, utensílios e profissionais prestadores de serviços. Sobre o compartilhamento de pastos, foi constatado que essa prática se configura como um fator de risco associado à infecção pelo HVB-1 $(\mathrm{OR}=2,9 ; \mathrm{p}=0,004)$.

Os resultados indicam que $100 \%$ das propriedades apresentaram ao menos um animal positivo para as duas infecções e que a ocorrência das infecções em bovinos na região foi elevada, visto que das 18 propriedades, 14 (77,8\%) apresentaram uma ocorrência de anticorpos classificada entre média a alta para HVB-1 e que das mesmas 18, 16 tiveram uma positividade de $100 \%$ para o VDVB-1.

As variáveis aquisição de animais destinados à reprodução $(\mathrm{OR}=4,2 ; \mathrm{p}<0,001)$ e reposição de animais da mesma região $(\mathrm{OR}=3,0 ; \mathrm{p}=0,001)$ foram apontados, neste, assim como em outros estudos (Segura-Correa et al., 2010; Dias et al., 2013; Silva et al., 2015), como fatores de risco associados à ocorrência da infecção pelo HVB-1. Isto pode estar relacionado ao fato de todas as propriedades amostradas apresentarem ao menos um animal positivo, somado ainda que as propriedades são próximas umas das outras, o que favorece o compartilhamento de pastagens aliado ao fato de ser comum na região a prática de venda de animais sem o devido exame sorológico.

No tocante ao manejo reprodutivo, a não utilização de biotécnicas reprodutivas, como a Inseminação artificial $(\mathrm{OR}=2,3 ; \mathrm{p}<0,001)$ e a transferência de embriões $(\mathrm{OR}=13,6 ; \mathrm{p}<0,001)$ se mostraram como fatores de risco associados à infecção pelo HVB-1 nas propriedades que não fazem uso dessas práticas. Por ser dirigido um melhor manejo sanitário aos animais provenientes das centrais de inseminação, de acordo com Instrução Normativa SDA No 48/2003 (BRASIL, 2003), a utilização dessas biotécnicas reprodutivas se apresentam como fatores de proteção para os animas, uma vez que o HVB-1 pode ser eliminado pelo sêmen e para a aplicação dessas técnicas existe um tratamento do mesmo.

O destino dos fetos abortados, se deixados no pasto, foi identificado como fator de risco associado à infecção pelo HVB-1 (OR= 4,0; $\mathrm{p}<$ 0,001 ). Os fetos abortados são uma importante fonte de transmissão para os animais hígidos, uma vez que a carga viral presente nos fetos, bem como anexos fetais, é bastante elevada.

Finalmente, um entendimento não apenas da biologia, mas também de fatores socioculturais como o comportamento humano e os motivos que fazem as partes interessadas adotarem ou não determinadas medidas (Lindberg e Houe, 2005) são cruciais para a planificação de estratégias de prevenção e controle tanto do HVB-1 como do VDVB-1.

\section{Conclusão}

A infecção tanto pelo VDVB-1, quanto pelo HVB-1 está distribuída em bovinos da bacia leiteira do estado de Pernambuco. Recomenda-se a adoção de medidas profiláticas que visem à proteção dos rebanhos bovinos, a partir dos fatores de risco identificados para HVB-1. Com relação ao VDVB-1, é importante que se identifiquem, inicialmente, a presença de animais PI dentro dos rebanhos, seguido de sua remoção sistemática. Para tanto, é preciso que se leve em consideração os fatores econômicos e sociais dos produtores, para que as devidas medidas profiláticas sejam aplicadas, e que esses incorporem à sua rotina o hábito da realização de exames sorológicos para o monitoramento do rebanho. 


\section{Conflito de interesse}

Todos os autores declaram que não existe conflito de interesse.

\section{Comissão de Ética}

O presente estudo foi aprovado pelo Comitê de Ética no Uso de Animais da Universidade Federal Rural de Pernambuco sob o número de licença 033/2015.

\section{Agradecimentos}

Ao professor Roberto Soares de Castro, do departamento de virologia da Universidade Federal Rural de Pernambuco por todo o suporte prestado.

\section{Referências}

Baker, J.C. 1995. The clinical manifestations of bovine viral diarrhea infection. Veterinary Clinics of North America: Food Animal Practice, 11(3): 425-445, 1995.

Barbosa, A.C.V.C.; Brito, W.M.E.D.; ALFAIA, B.T. Soroprevalência e fatores de risco para a infecção pelo herpesvírus bovino tipo 1 (BHV-1) no Estado de Goiás, Brasil. Ciência Rural, 35(6): 1368-1373, 2005.

BRASIL. Instituto Brasileiro de Geografia e Estatística. Produção da Pecuária Municipal: 2015. Disponível em: <http://www.cidades.ibge.gov.br/cartograma/ mapa.php?lang $=\&$ coduf $=26$

$\&$ codmun $=260050 \&$ idtema $=159 \& \operatorname{codv}=\mathrm{v} 13$

$\&$ search=pernambuco|\%C3\%81 guas-belas $\mid$

sintese-das-informacoes-2015>. Acesso em: 05 out. 2016.

BRASIL. Ministério da Agricultura, Pecuária e Abastecimento. Instrução Normativa SDA No 48 de 17 de junho de 2003. Disponível em:

<http://www3.servicos.ms.gov.br/iagro_ged/ pdf/214_GED.pdf $>$. Acesso em: 13 mai. 1016.

Castro, R.S.; Melo, L.E.H.; Abreu, S.R.O; Muniz, A.M.M.; Albuquerque, A. P. S. Anticorpos neutralizantes contra o pestivirus em soros bovinos do estado de Pernambuco. Pesquisa Agropecuária Brasileira, 28(11): 13271331, 1993.

Chaves, N.P.; Bezerra, D.C.; Sousa, V.E. Santos, H.P. Pereira, H. de M. Frequência e fatores de risco associados à infecção pelo vírus da Diarreia Viral Bovina em bovinos leiteiros não vacinados no estado do Maranhão.
Arquivos do Instituto Biológico, 79(4): 495 502, 2012.

Chowdhury, M.M.R.; Afrin, F.; Saha, S.S.; Jhontu, S.; Asgar, M.A. Prevalence and haematological parameters for bovine viral diarrhoea (BVD) in South Bengal áreas in Bangladesh. The Bangladesh Veterinarian, 32(2): 48-54, 2015.

Dias, J.A.; Alfieri, A.A.; Ferreira-Neto, J.S.; Gonçalves, V.S.P. Muller, E.E. Seroprevalence and Risk Factors of Bovine Herpesvirus 1 Infection in Cattle Herds in the State of Paraná, Brazil. Transboundary and Emerging Diseases, 60(1): 39-47, 2013.

Evans, C.A.; Cockcroft, P.D..; Reichel, M.P. Antibodies to bovine viral diarrhoea virus (BVDV) in water buffalo (Bubalus bubalis) and cattle from the Northern Territory of Australia. Australian Veterinary Journal, 94(11): 423-426, 2016.

Freitas, E.J.; Lopes, C.E.R.; Moura Filho, J.M.; Sá, J.S.; Santos, H.P.; Pereira, H.M. Frequência de anticorpos contra o herpesvírus bovino tipo 1 (BoHV-1) em bovinos de corte não vacinados. Semina: Ciências Agrárias, 35(3): 1301-1310, 2014.

Grooms, D.L. Reproductive consequences of infection with bovine viral diarrhea virus. Veterinary Clinics of North America: Food Animal Practice, 20(1): 5-19, 2004.

Guarino, H.; Núñez, A.; Repiso, M.V.; Gil, A.; Dargatz, D.A. Prevalence of sérum antibodies to bovine herpesvirus-1 and bovine viral diarrea virus in beef cattle in Uruguay. Preventive Veterinary Medicine, 85(1-2): 34-40, 2008.

Holz, C.L.; Cibulski, S.P.; Teixeira, T.F.; Batista, H.B.C.R.; Campos, F.S.; Silva, J.R.; Varela, A.P.M.; Cenci, A.; Franco, A.C.; Roehe, P.M. Soroprevalência de herpesvírus bovinos tipos 1 e/ou 5 no Estado do Rio Grande do Sul. Pesquisa Veterinária Brasileira, 29(9): 767773, 2009.

Hosmer, D.W.; Lemeshow, S. Applied logistic regression. $1^{\text {st }}$ ed. New York: John Wiley \& Sons, 1989. 307p.

Houe, H.; Baker, J.C.; Maes, R.K.; Wuryastuti, H.; Wasito, R.; Ruegg, P.L.; Lloyd, J.W. Prevalence of cattle persistently infected with bovine viral diarrea virus in 20 dairy herds in two counties in central Michigan and comparison of prevalence of antibodypositive cattle among herds with diferent 
infection and vaccination status. Journal of Veterinary Diagnostic Investigation, 7(3): 321-326, 1995.

Kirkbride, C.A. Viral agents and associated lesions detected in a 10-year study of bovine abortions and stillbirths. Journal of Veterinary Diagnostic Investigation, 4(4): 374-379, 1992.

Lindberg, A.: Houe, H. Characteristics in the epidemiology of bovine diarrhea virus (BVDV) of relevance to control. Preventive Veterinary Medicine, 72(1-2): 55-73, 2005.

Muylkens, B.; Thiry, J.; Kirten, P.; Schynts, F.; Thiry, E. Bovine herpesvirus 1 infection and infectious bovine rhinotracheitis. Veterinary Research, 38(2): 181-209, 2007.

Nandi, S.; Kumar, M; Manohar, M.; Chauhan, R.S. Bovine herpes virus infection in cattle. Animal Health Research Reviews, 10(1): 85-89, 2009.

OIE. World Organization for Animal Health. Infectious bovine rhinotracheitis/infectious pustular vulvovaginitis. In: Manual of diagnostic tests and vaccines for terrestraial animals. $7^{\text {th }}$ ed. Paris: OIE, 2017. cap. 2.4.12, p. 1-19. Disponível em: $<$ http://www.oie.int/international-standardsetting/terrestrial-manual/access-online/>.

Acesso em: 23 out. 2017.

Oliveira, R.A.; Lorenzetti, E.; Alfieri, A.A.; Lisbôa, J.A.N. Prevalência das infecções latentes por BoHV-1 e BoHV-5 em bovinos de corte no Estado do Paraná. Arquivo Brasileiro de Medicina Veterinária e Zootecnia, 67(5): 1217-1225, 2015.

Ribeiro, M.B.; Galvão, C.L.; Costa, A.R.; Rodrigues, F.M.; Suzart, J.C.C. Infecções pelo vírus da rinotraqueíte infecciosa bovina/vulvovaginitepustular infecciosa, diarréia viral bovina e parainfluenza-3, detectadas por meio de avaliação sorológica no estado da Bahia. Salvador: Empresa de Pesquisa Agropecuária da Bahia, 1987. 30p.

Romero-Salas, D.; Ahuja-Aguirre, C.; MontielPalacios, F.; García-Vázquez, Z.; CruzRomero, A.; Aguilar-Domínguez, $\mathrm{M}$. Seroprevalence and risk factors associated with infectious bovine rhinotracheitis in unvaccinated cattle in southern Veracruz, Mexico. African Journal of Microbiology Research, 7(17): 1716-1722, 2013.

Santos, M.R.; Ferreira, H.C.C.; Santos, M.A.; Saraiva, G.L.; Tafuri, N.F.; Santos, G.M.; Tobias, F.L.; Moreira, M.A.S.; Almeida, M.R.; Silva Júnior, A. Antibodies against bovine herpesvirus1 in dairy herds in the state of Espirito Santo, Brasil. Revista Ceres, 61(2): 280-283, 2014.

Sayers, R.G.; Byrne, N.; O'Doherty, E.; Arkins, S. Prevalence of exposure to bovine viral diarrhoea virus (BVDV) and bovine herpesvirus-1 (BoHV-1) in Irish dairy herds. Research in Veterinary Science, 100: 21-30, 2015.

Segura-Correa, J.C.; Solorio-Rivera, J.L.; Sánchez-Gil, L.G. Seroconversion to bovine viral diarrhea virus and infectious bovine rhinotracheitis virus in dairy herds of Michoacan, Mexico. Tropical Animal Health and Production, 42(2): 233-238, 2010.

Silva, F.S.; Oliveira, J.M.B.; Batista Filho, A.F.B.; Ribeiro, C.P.; Pituco, E.M. Pinheiro Junior, J.W. Análise epidemiológica da infecção pelo herpesvírus bovino tipo 1 (BoHV-1) em bovinos no Estado de Pernambuco. Acta Scientiae Veterinarie, 43: 1324, 2015.

Thrusfield, M. Epidemiologia veterinária. $2^{\mathrm{a}} \mathrm{ed}$. São Paulo: Roca, 2004. 558p. 